\title{
LIPOMA OF THE SUBMANDIBULAR SPACE
}

Sathyaki D.C1, Jyothi Swarup. R², Mohan. M³, Rekha. A. Varghese ${ }^{4}$.

1. Assistant Professor, Department of E.N.T, Sri Siddhartha Medical College, Tumkur.

2. Associate professor, Department of E.N.T, Sri Siddhartha Medical College, Tumkur.

3. Professor, Department of E.N.T, Sri Siddhartha Medical College, Tumkur.

4. Junior Resident, Department of E.N.T, Sri Siddhartha Medical College, Tumkur.

\section{CORRESPONDING AUTHOR}

Sathyaki D.C,

Department of E.N.T,

Sri Siddhartha Medical College,

Agalkot E, B.H.Road,

Tumkur,Karnataka- 572107.

Email-sathyaki_dc@Yahoo.co.in

HOW TO CITE THIS ARTICLE:

Sathyaki D.C, Jyothi Swarup. R, Mohan. M, Rekha. A. Varghese. "Lipoma of the Submandibular Space". Journal of Evolution of Medical and Dental Sciences 2013; Vol2, Issue 24, June 17; Page: 4329-4331.

ABSTRACT: Lipomas in the submandibular space are uncommon. This report describes a case of lipoma in the submandibular space. The clinical features, imaging study, histopathological features and management of the tumour, are described.

INTRODUCTION: Lipomas of the submandibular space are relatively uncommon. Conventionally lipomas are divided into three types. Superficial lipomas (arise within subcutaneous tissue), deep lipoma (arise within deep soft tissue) and parosteal lipoma (arise within surfaces of the bone) 3 . Although lipomas are generally diagnosed by clinical examination the imaging studies and histopathological examination can aid in establishing the diagnosis.

CASE REPORT: A 55-year old male patient presented with a swelling of the right submandibular region since two years. The swelling was painless and gradually progressive. Clinical examination revealed a smooth surfaced, soft, non tender mass $(3 \times 3 \mathrm{~cm})$ with well defined margins in the right submandibular region. The swelling was mobile not fixed to the skin and underlying bone. Clinically submandibular region swelling could be lymph node or glandular enlargement was suspected.

Ultrasonography of the right submandibular region showed a well circumscribed, elliptical mass which was relatively hyperechoic to the adjacent muscle which was adjacent to the base of the mandible. Fine needle aspiration cytology showed fragments of adipose tissue consisting of cells with large vacuole of fat and small peripherally located nuclei. Fragments also contained capillary vessels. It was negative for malignancy.

The patient underwent standard submandibular gland approach under local anaesthesia with sedation. Excised mass showed a well-circumscribed lesion that was easily separated from the surrounding tissues. Rest of the gland was normal. Marginal mandibular nerve was well preserved. Histopathological examination of the specimen showed adipocytes in lobules, separated by fibro 


\section{CASE REPORT}

connective tissue and muscle bundles were noted. These features were suggestive of superficial lipoma.

DISCUSSION: Although Lipomas are relatively uncommon in the head and neck region they should be kept as one of the differential diagnosis of neck mass. Furlong et al in their study reported that lipomas in the head and neck are common in the parotid region followed by buccal mucosa and lip5. There have been reports of deep intra muscular lipoma in the submandibular region by Adachi etal1. Pusiol etal reported an oncocytic sialolipoma of submandibular gland2.

Lipomas, lipomatosis, angiolipomas, chondroid lipomas, lipoblastoma, lipobalostomatosis, spindle cell lipoma and pleomorphic lipomas are lesions that can mimic the condition. The solitary lipoma is common soft tissue tumours that result due to proliferation of histologically and chemically normal adipose tissue. Solitary lipoma is not developmental in origin and hence not considered as a Hamartoma, but rather a true neoplasm4.

When it comes to the diagnosis, sometimes clinical examination alone is not sufficient to identify the nature and exact location of the mass. In such a situation, imaging and histopathological examination can be useful. Ultrasound and magnetic resonance imaging can differentiate lipomas from other soft tissue tumours. In the case reported here, ultrasonography and histopathological examination were useful for the diagnosis. The prognosis of superficial lipoma is good and the risk of recurrence is low.

\section{BIBLIOGRAPHY:}

1. Adachi P, Kaba SP, Soubhia AM, Shinohara EH. Intermuscular lipoma of the submandibular space. Indian journal of dental research. 2011 Nov; 22(6):871-2.

2. Pusiol T, Franceschetti I, Scialpi M, Piscioli I. Oncocytic sialolipoma of the submandibular gland with sebaceous differentiation: a new pathological entity. Indian journal of pathology and microbiology. 2009 Jul; 52(3):379-82.

3. Gultekin SE, Kahraman S, Karady K. Parosteal osteochondrolipoma of the mandible. Journal of oral and maxillofacial pathology. 2012 May; 16(2):280-2

4. Hemavathy S, Roy S, Kiresur A. Intraosseous angiolipoma of the mandible. Journal of oral and maxillofacial pathology. 2012 May; 16(2):283-7.

5. Furlong MA, Fanburg-Smith JC, Childers EL. Lipoma of the oral and maxillofacial region: Site and subclassification of 125 cases. Oral surgery oral medicine oral pathology oral radiology endodontics. 2004; 98: 441-50. 


\section{CASE REPORT}

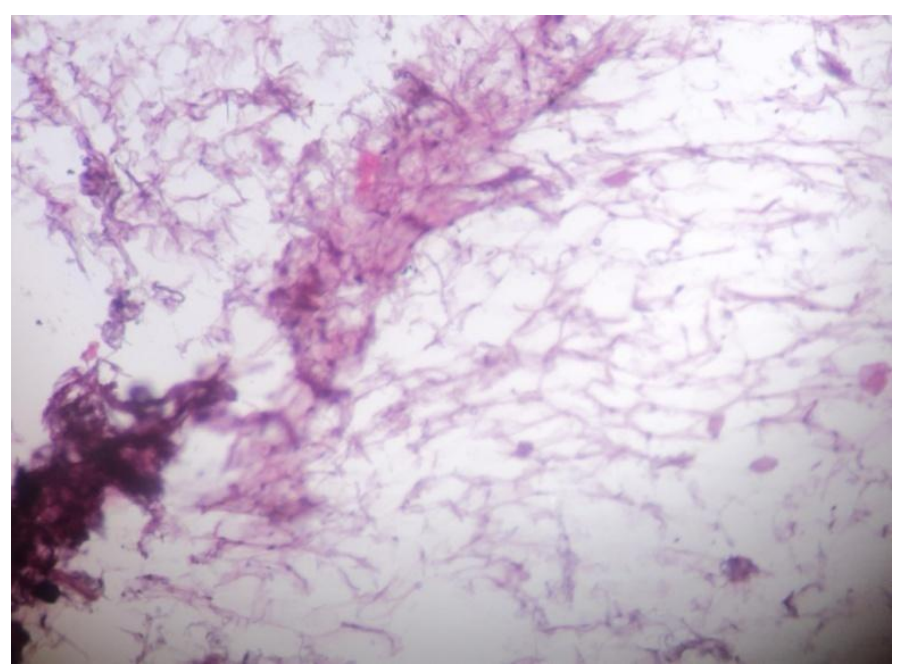

Histopathological Examination

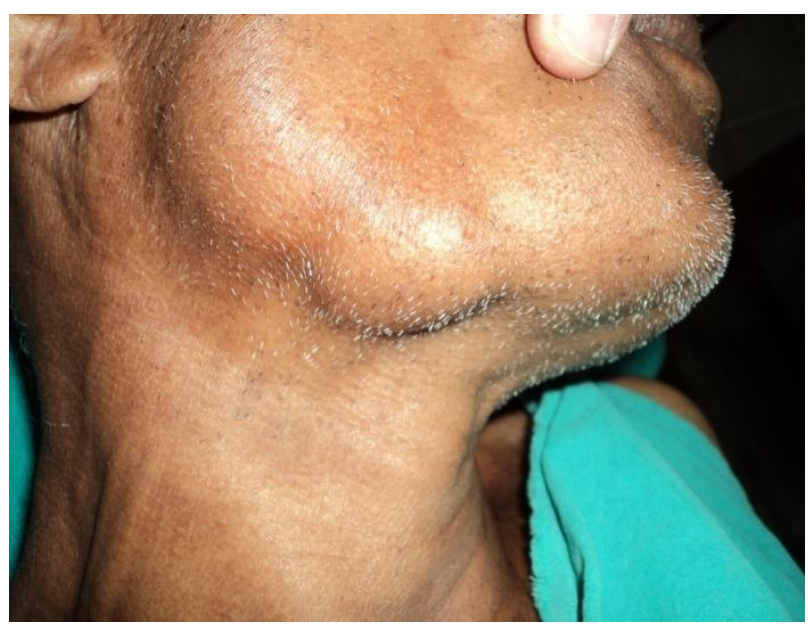

Superficial lipoma of submandibular space 001

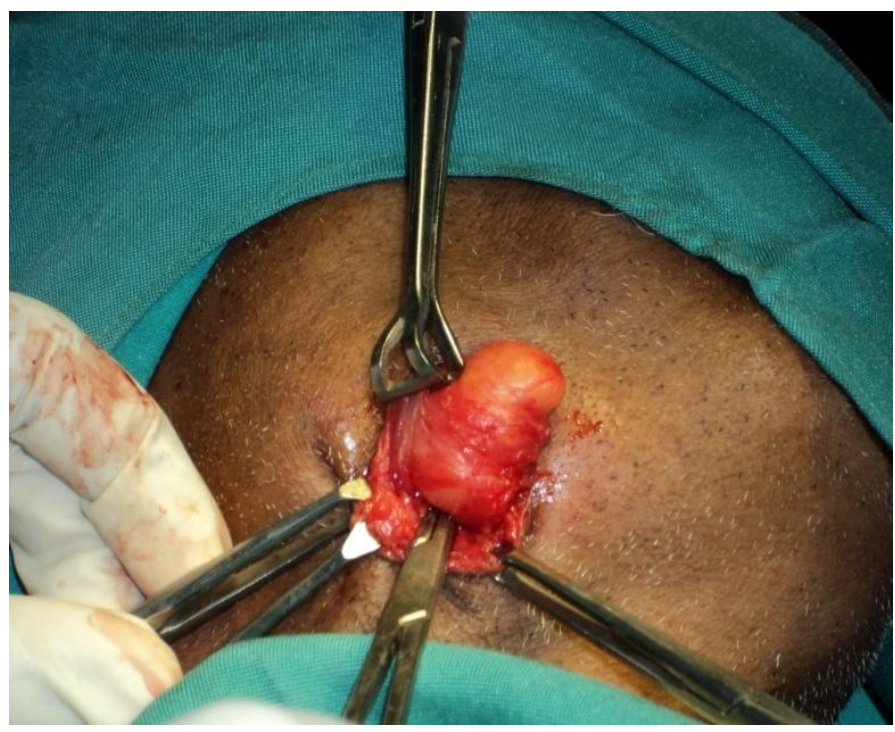

Superficial lipoma of submandibular space 004 